\title{
Case-control study examining the impact of oral health problems on the quality of life of the families of preschoolers
}

\section{Ramon Targino FIRMINO(a) Monalisa Cesarino GOMES(b) Raquel Gonçalves VIEIRA-ANDRADE(a) Carolina Castro MARTINS(a) Saul Martins PAIVA(a) Ana Flávia GRANVILLE-GARCIA(b)}

(a) Universidade Federal de Minas Gerais - UFMG, School of Dentistry, Department of Pediatric Dentistry and Orthodontics, Belo Horizonte, MG, Brazil.

(b)Universidade Estadual da Paraíba - UEPB, Department of Dentistry, Campina Grande, PB, Brazil.

Declaration of Interests: The authors certify that they have no commercial or associative interest that represents a conflict of interest in connection with the manuscript.

Corresponding Author: Ana Flávia Granville-Garcia E-mail: anaflaviagg@hotmail.com

DOI: 10.1590/1807-3107BOR-2016.vol30.0121

Submitted: Dec 14, 2015

Accepted for publication: Aug 16, 2016

Last revision: Aug 30, 2016
Abstract: The aim of this study was to evaluate the impact of dental caries, traumatic dental injuries (TDI), toothaches, and malocclusion on the oral health-related quality of life (OHRQoL) of the families of Brazilian preschool children. A population-based, matched case-control study involving 415 pre-schoolers aged 3-5 years was conducted. The case (impact on OHRQoL) and control groups (no impact on OHRQoL) were matched for age, gender, and family income at an 1:4 ratio. Impact on the OHRQoL of a family was assessed using the Brazilian version of the Early Childhood Oral Health Impact Scale (B-ECOHIS). Dental caries, TDI, and malocclusion were diagnosed by three calibrated dentists (Kappa: 0.85-0.90). Data analysis involved descriptive statistics and conditional logistic regression analysis ( $\mathrm{p} \leq 0.05$; 95\%CI). There were no differences between the cases and controls regarding age, gender, and family income $(\mathrm{p}>0.05)$. The most frequent responses on the B-ECOHIS among cases were "felt guilty" (68.6\%) and "been upset" (48.2\%). The following variables were significantly associated with negative impacts on family OHRQoL (cases): caries severity $(\mathrm{OR}=6.680 ; 95 \% \mathrm{CI}=2.731-16.349)$, a history of toothache $(\mathrm{OR}=2.666$; $95 \% \mathrm{CI}=1.492-4.765)$, parental rating of the child's oral health as poor (OR: 1.973; 95\%CI = 1.072-3.634), and parent's/caregiver's age $(\mathrm{OR}=2.936 ; 95 \% \mathrm{CI}=1.077-3.478)$. Anterior open bite was positively associated with OHRQoL $(\mathrm{OR}=4.050 ; 95 \% \mathrm{CI}=1.333-12.314)$. Caries severity, a history of toothache, parental rating of the child's oral health as poor, and younger parents/caregivers were associated with impact on the OHRQoL of the families of preschoolers.

Keywords: Case-Control Studies; Dental Caries; Family Health; Quality of Life; Tooth Injuries.

\section{Introduction}

Parents/caregivers play a central role in ensuring the wellbeing of young children and are usually responsible for making decisions regarding matters affecting their child's health. ${ }^{1,2}$ Thus, it is important to assess the impact of oral health issues in children on the quality of life of their families because illness and injury can affect the emotional wellbeing of families and, consequently, the child's use of dental services and the promotion of their oral health. ${ }^{1,3,4}$ 
Investigations have shown that oral health problems such as dental caries, traumatic dental injury (TDI), toothache, and malocclusion in children can have negative consequences on the family, such as feelings of guilt, irritation, financial problems, and loss of time and workdays for parents/caregivers. $5,6,7,8$ However, most of these studies jointly evaluated impacts on the child and family ${ }^{9,10}$ or focused only on specific consequences such as parental guilt.7.8 A focused examination of the impact on family would contribute to a deeper understanding of this issue and also support health interventions. Moreover, a majority of the studies examining this issue employ a cross-sectional design, which does not allow inference of causality. ${ }^{11}$ Conversely, case-control studies allow estimation of the strength of the association between an event and risk factors, and matched case-control groups allow us to control confounding variables and also result in a smaller sample size that enhances the precision and power of the study. ${ }^{12}$ To date, no matched case-control study has focused on factors associated with the impact of oral health problems in preschool children on the quality of life of their families.

The aim of the present matched case-control study is to evaluate the impact of dental caries, TDI, toothache, and malocclusion on the oral health-related quality of life (OHRQoL) of the families of Brazilian preschool children.

\section{Methodology}

This study was conducted in accordance with the Declaration of Helsinki, and was independently reviewed and approved by the Human Research Ethics Committee of the State University of Paraiba (Brazil) (protocol number 0046.0.133.000-11). Parents/guardians received information regarding the objectives of the study and also provided written informed consent.

\section{Eligibility Criteria}

This study included children aged three to five years enrolled in public or private preschools or day care centers, who did not suffer from any systematic diseases (based on the parents/caregiver's report), and were accompanied by a parent/caregiver who spoke Brazilian Portuguese. The exclusion criteria were four maxillary incisors lost due to caries or physiological exfoliation as this could compromise a clinical diagnosis of TDI.

\section{Sample Characteristics and Study Design}

The study included a population-based, matched case-control sample consisting of 415 preschoolers enrolled at public and private preschools in the city of Campina Grande, Brazil. This study was nested in a previous cross-sectional investigation that involved 843 children of the same age randomly selected from a representative sample using a two-phase random sampling strategy. ${ }^{13}$ Campina Grande is an industrialised city located in northeast Brazil and is divided into six administrative districts with a mean monthly income of approximately US\$ 110 per capita and a Human Development Index of 0.72. ${ }^{14}$

The software Epi Info 6.04 (Centers for Disease Control and Prevention, Atlanta, GA, USA) was used to determine the minimum sample size needed for this case-control study. The following parameters were employed: power of $80.0 \%$, standard error of $5.0 \%$, and estimated $54.0 \%$ and $37.5 \%$ prevalence rates of caries in the case and control groups, respectively. These characteristics were determined in a pilot study. Guidelines for sample size calculation have established that using a $50 \%$ prevalence rate in the formula yields the maximum value of $\mathrm{n}$, representing a sample large enough for the desired reliability and interval width. . $1,16^{-16}$ Thus, the $54 \%$ prevalence rate used in the present study yielded a sample large enough to investigate the three oral conditions under study (dental caries, TDI and malocclusion). Considering four controls for each case, the minimum sample size to satisfy the requirements was 83 cases and 332 controls.

\section{Selection of Cases and Controls}

The Early Childhood Oral Health Impact Scale (ECOHIS) is an assessment tool designed to evaluate the impact of oral conditions on the OHRQoL of children aged two to five years and their families. ${ }^{2}$ This questionnaire has been translated into Portuguese and validated for use on Brazilian populations (B-ECOHIS), ${ }^{17,18,19}$ and has been employed in several previous studies. ${ }^{10,17,20} \mathrm{It}$ is a proxy measure that uses the reports of parents/caregivers and is divided into 
two sections (Child Impact and Family Impact). Since the aim was to evaluate the impact of oral health problems on the family OHRQoL, the Child Impact Section was not used in the present study. The Family Impact Section has four items distributed over two domains: parental distress (two items) and family function (two items). Each item has six response options: never, hardly ever, occasionally, often, very often, and do not know.

Sample selection was carried out by two researchers (RTF and MCG). Of the original 843 children, 14 were excluded for having one or more "do not know" responses on the Family Impact Section of the B-ECOHIS and 92 were excluded for having missing information on independent variables. Of the remaining 737 children, 187 (25.4\%) who exhibited impact on OHRQoL were considered eligible to be selected for the case group, while 550 (74.6\%) who exhibited no impact on OHRQoL were considered eligible for the control group. The outcome variable "impact on family OHRQoL" was used to define cases and controls. Children with B-ECOHIS items for which responses were "occasionally" (score 2), "often" (score 3), or "very often" (score 4) on at least one question were categorised as having a negative impact on OHRQoL (case group), whereas those with responses of "never" (score 0) or "hardly ever" (score 1) for all items were categorised as having a non-negative impact on OHRQoL (control group) (Table 1). ${ }^{18}$ Cases and controls were matched by age, gender, and monthly household income (categorised based on the monthly minimum salary of US\$312.50 in Brazil) at a 1:4 ratio.
To preserve the representativeness of the data, the selection of children for the case and control groups was performed maintaining the proportion of children in each region (6 districts within the city limits plus surrounding rural areas) of the city of Campina Grande. ${ }^{13}$

\section{Training and Calibration Exercise}

The training and calibration exercise consisted of two steps (theoretical and clinical). The theoretical step involved a discussion of the criteria for the diagnosis of dental caries, TDI, malocclusion and an analysis of photographs. A specialist in pediatric dentistry (gold standard in this theoretical framework) coordinated this step, instructing three general dentists on how to perform the examination. The clinical step was performed at a randomly selected preschool that was not part of the main sample. Each dentist examined 50 previously selected preschool children, aged three to five years, from the main sample. Data analysis involved calculation of Cohen's Kappa coefficients on a tooth-by-tooth basis. Inter-examiner agreement was tested by comparing each examiner to the gold standard $(\mathrm{K}=0.83$ to 0.88$)$. After a seven-day interval, the examinations were performed a second time for the determination of intra-examiner agreement ( $K=0.85$ to 0.90$)$. As the Kappa coefficients were very good, ${ }^{21}$ the examiners were considered capable of performing the epidemiological study.

Table 1. Distribution of responses to Brazilian version of Early Childhood Oral Health Impact Scale (B-ECOHIS) among preschool children in the case and control groups.

\begin{tabular}{|c|c|c|c|c|}
\hline \multirow{3}{*}{$\begin{array}{l}\text { B-ECOHIS } \\
\text { Domains, Items }\end{array}$} & \multicolumn{2}{|c|}{ Case group $(n=83$ ) } & \multicolumn{2}{|c|}{ Control group ( $n=332$ ) } \\
\hline & Never or hardly ever & $\begin{array}{l}\text { Occasionally, often, } \\
\text { or very often }\end{array}$ & Never or hardly ever & $\begin{array}{l}\text { Occasionally, often, } \\
\text { or very often }\end{array}$ \\
\hline & \multicolumn{4}{|c|}{ n (\%) } \\
\hline \multicolumn{5}{|l|}{ Family Impact } \\
\hline \multicolumn{5}{|l|}{ Parental distress domain } \\
\hline Been upset & $43(51.8)$ & $40(48.2)$ & $332(100.0)$ & $0(0)$ \\
\hline Felt guilty & $26(31.3)$ & $57(68.6)$ & 332 (100.0) & $0(0)$ \\
\hline \multicolumn{5}{|l|}{ Family function domain } \\
\hline Taken time off work & $65(78.3)$ & $18(21.7)$ & $332(100.0)$ & $0(0)$ \\
\hline Financial impact & $72(86.7)$ & $11(13.3)$ & $332(100.0)$ & $0(0)$ \\
\hline
\end{tabular}




\section{Pilot Study}

A pilot study was performed to test the methodology and comprehension of the questionnaires. The children in the pilot study $(n=40)$ were not included in the main sample. As there were no misunderstandings regarding the questionnaires or the methodology, no changes to the data collection process were deemed necessary.

\section{Non-Clinical Data Collection}

Non-clinical data were acquired through administration of the B-ECOHIS as well as questionnaires collecting socio-demographic and child health data. Monthly household income was collected in crude value and then dichotomized by the median (up to one and more than one Brazilian minimum wage). All questionnaires were filled out by the parents/caregivers and returned to the researchers.

The following socio-demographic variables were analysed: parent/guardian's age, mother's schooling, and type of preschool (public or private). The following child health data were analysed: history of toothache, history of dental visits, and parent/caregivers perceptions regarding their child's general and oral health. The latter item was analysed based on answers to the following question: In general, how would you describe your child's general health/oral health? The response options were 1) very good, 2) good, 3) fair, 4) poor, and 5) very poor. For statistical purposes, these answers were dichotomised as good (codes 1 and 2) and poor (codes 3, 4 and 5). ${ }^{10}$

\section{Clinical Data Collection}

The clinical examination was carried out at the preschools after the caregivers had returned the questionnaires and signed statements of informed consent and was performed by three dentists who had undergone the training and calibration exercise. Prior to the exam, each child received a kit containing a toothbrush, toothpaste, and dental floss to remove bacterial plaque from the teeth and facilitate diagnosis. The examinations were performed with the child seated in front of the examiner and illuminated by a portable lamp positioned on the examiner's head (Petzl Zoom head lamp, Petzl America, Clearfield, UT, USA).
The dentists used individual protection equipment, a sterilised mouth mirror (PRISMA®, São Paulo, SP, Brazil), sterilised Williams probe (WHO-621, Trinity ${ }^{\circledR}$, Campo Mourão, PA, Brazil), and gauze to dry the teeth.

Dental caries were diagnosed using the International Caries Detection and Assessment System (ICDAS II) ${ }^{22}$ which is a scoring system ranging from 0 (absence of dental caries) to 6 . Due to the epidemiological nature of the present study, code 1 was not used as drying of the teeth was performed with gauze rather than compressed air. Code 2 was used for white spots, and codes $\geq 3$ represented increasing degrees of cavitation. For statistical purposes, dental caries was dichotomised as absent (code 0 ) or present (code $\geq 2$ ) (24). Caries severity was also considered in the evaluation of the impact of dental caries on OHRQoL. This variable was categorised into no cavitated lesions and/or with white spots, low severity (up to 5 cavitated lesions), and high severity (6 or more cavitated lesions).

A diagnosis of TDI included enamel fracture, enamel + dentine fracture, complicated crown fracture, extrusive luxation, lateral luxation, intrusive luxation, and avulsion. ${ }^{23} \mathrm{~A}$ visual inspection for tooth colouration was also performed, and a diagnosis of TDI was recorded if any type of TDI or tooth discolouration was observed.

A diagnosis of malocclusion was made if at least one of the following conditions were observed: increased overbite $(>2 \mathrm{~mm})$, increased overjet $(>2 \mathrm{~mm})$, anterior open bite, and anterior crossbite. ${ }^{24,25}$ Following examination, a fluoridated varnish was applied to the teeth and children with dental caries or other dental needs were sent for treatment.

\section{Statistical Analysis}

Data organisation and statistical analyses were performed using the Statistical Package for Social Sciences (SPSS for Windows, version 21.0, IBM Inc, Amonk, NY, USA). Frequency distributions were used to characterise the sample and demonstrate the distribution of the B-ECOHIS items. Impact on OHRQoL was classified as 'no' for responses of "never" and "hardly ever" or "yes" for responses of 
"occasionally," "often," and "very often." 2 The level of significance was set at $5 \%(p<0.05)$. Explanatory variables with a $p$-value $\leq 0.20$ in the bivariate analysis were incorporated into the conditional logistic regression model. Unadjusted and multiple conditional logistic regressions were performed using the backward stepwise method. Effect sizes $\left(\eta^{2}\right)$ were calculated for variables that remained in the final logistic regression model.

\section{Results}

No statistically significant differences in the frequency distribution of variables used for matching (gender, age and monthly family income; $\mathrm{p}>0.05$ ) were observed between the groups. No participants were excluded from the study for lack of cooperation during the clinical exam.

Table 1 presents the responses of the B-ECOHIS questions (Family Impact Section) for the case and control groups. In the case group, the most prevalent items affecting the family's quality of life were related to feeling guilty $(68.6 \%)$ and being upset $(48.2 \%)$.

In the final conditional logistic regression model, caries severity, a history of tooth pain, parent's/caregiver's age, and parent's/caregiver's perception of the child's oral health were associated with a negative impact on the family's OHRQoL. The presence of anterior open bite was a protective factor for family impact (Table 2).

\section{Discussion}

The importance of this investigation lies in the fact that it is the first case-control study to jointly investigate the impact of dental caries, toothache, TDI, and malocclusion on the quality of life of the families of preschoolers. Previous case-control studies have investigated the role of oral health problems on OHRQoL. ${ }^{26,27,28}$ However, these studies focused on older children/adolescents ${ }^{26,27,28}$ and defined cases and controls based on clinical conditions (TDI and malocclusion). ${ }^{26,27}$ As the aim or our study was to investigate the influence of oral conditions on family OHRQoL (outcome variable), we classified groups based on the presence (cases) or absence (controls) of a negative family impact.
A high severity of caries was more frequent among cases. As expected, the final model showed that families with children presenting six or more carious lesions (high severity) were approximately seven times more likely to experience impact on their quality of life, in accordance with previous cross-sectional Brazilian studies ${ }^{5,6,7,13,20}$.This may stem from the fact that the progression of caries implies more complicated treatment, which can result in the loss of work days for parents and financial problems for the family. ${ }^{2,5,6}$ Additionally, caries severity often results in unsightly appearance, which may concern parents/caregivers with regard to opportunities in the child's future life. ${ }^{6}$ Severe caries can also lead to dental pain ${ }^{29}$ which is associated with family impact, as demonstrated by our findings and previous cross-sectional investigations. ${ }^{8,13}$ This may have occurred because parents may feel guilty and fear being blamed for their children's oral problems , $^{7,30}$ or because the child may require extra attention to relieve discomfort, which can cause parental distress. ${ }^{6}$ Indeed, parents/caregivers of children in the case group reported feelings of guilt and being upset.

The control group had a significantly higher frequency of anterior open bite (AOB) when compared to the case group. The present case-control study is the first investigation to show that the presence of $\mathrm{AOB}$ is a protective factor for impact on the family's quality of life. The literature is clear about the causal pathway between occlusal traits such as $\mathrm{AOB}$ and non-nutritive habits like thumb and pacifier sucking. ${ }^{30}$ Given that such oral habits provide comfort and satisfaction and help the child calm down, ${ }^{32}$ children with such habits, and thus with $\mathrm{AOB}$, tend not to distress their parents, thereby explaining the absence of impact. Moreover, parents may not perceive malocclusion in primary teeth (children were 3-5 years old) as an oral problem. Other possible explanations rely on the fact that parents may think that malocclusion is hereditary, ${ }^{7}$ not perceiving it as a real problem in this age group. This may contribute to parents not seeking treatment, thus avoiding expenditures as well as the loss of time.

Parental age was unevenly distributed among cases and controls. Parents younger than thirty years of age had a three-fold greater chance of experiencing impact on their OHRQoL than their counterparts. This 
- Case-control study examining the impact of oral health problems on the quality of life of the families of preschoolers

Table 2. Conditional logistic regression analysis and effect sizes of independent variables in study groups.

\begin{tabular}{|c|c|c|c|c|c|c|c|}
\hline \multirow{3}{*}{ Independent variables } & \multicolumn{2}{|c|}{ Group } & \multirow{3}{*}{ p-value } & \multirow[b]{2}{*}{ Unadjusted } & \multirow{3}{*}{$p$-value ${ }^{* *}$} & \multirow[b]{2}{*}{ Adjusted } & \multirow{3}{*}{$\eta^{2}$} \\
\hline & \multirow{2}{*}{$\begin{array}{c}\text { Case } \\
(\mathrm{n}=83) \\
\mathrm{n}(\%)\end{array}$} & \multirow{2}{*}{$\begin{array}{c}\begin{array}{c}\text { Control } \\
(\mathrm{n}=332)\end{array} \\
\mathrm{n}(\%)\end{array}$} & & & & & \\
\hline & & & & OR $(95 \% \mathrm{Cl})$ & & OR $(95 \% \mathrm{Cl})$ & \\
\hline \multicolumn{8}{|l|}{ Dental Caries } \\
\hline Absent & $15(9.6)$ & $141(90.4)$ & $<0.001$ & 1 & - & - & - \\
\hline Present & $68(26.3)$ & $191(73.7)$ & - & 3.347 (1.837-6.098) & - & - & - \\
\hline \multicolumn{8}{|l|}{ Caries Severity } \\
\hline Caries free & $21(8.8)$ & $219(91.3)$ & - & 1 & - & - & - \\
\hline Low severity & $37(27.6)$ & $97(72.4)$ & $<0.001$ & $3.978(2.213-7.150)$ & 0.002 & $2.720(1.450-5.100)$ & 0.395 \\
\hline High severity & $25(61.0)$ & $16(39.0)$ & $<0.001$ & $16.296(7.538-35.223)$ & $<0.001$ & $6.680(2.731-16.349)$ & \\
\hline \multicolumn{8}{|c|}{ ( } \\
\hline Absent & $58(20.1)$ & $230(79.9)$ & 0.915 & 1 & - & - & - \\
\hline Present & 25 (19.7) & $102(80.3)$ & - & $0.972(0.576-1.641)$ & - & - & - \\
\hline \multicolumn{8}{|l|}{ Type of TDI } \\
\hline $\begin{array}{l}\text { Enamel fracture without } \\
\text { trauma }\end{array}$ & $71(20,1)$ & $282(79.9)$ & 0.978 & 1 & - & - & - \\
\hline Enamel + dentine fracture & $3(16.3)$ & $15(83.3)$ & 0.722 & $0.794(0.224-2.819)$ & - & - & - \\
\hline Avulsion and/or luxation & $1(16.7)$ & 5 (83.3) & 0.835 & $0.794(0.091-6.907)$ & - & - & - \\
\hline Discolouration & $8(21.1)$ & $30(78.9)$ & 0.891 & $1.059(0.465-2.410)$ & - & - & - \\
\hline \multicolumn{8}{|l|}{ Malocclusion } \\
\hline Absent & $59(26.6)$ & $163(73.4)$ & $<0.001$ & 1 & - & - & - \\
\hline Present & $24(12.4)$ & $169(87.6)$ & - & $2.549(1.514-4.292)$ & - & - & - \\
\hline \multicolumn{8}{|l|}{ Anterior Crossbite } \\
\hline Absent & $82(20.0)$ & $329(80.0)$ & 0.802 & 1 & - & - & - \\
\hline Present & $1(25.0)$ & $3(75.0)$ & - & $1.337(0.137-13.024)$ & - & - & - \\
\hline \multicolumn{8}{|l|}{ Anterior open bite } \\
\hline Present & $4(6.6)$ & $57(93.4)$ & 0.000 & 1 & - & 1 & \\
\hline Absent & 79 (22.3) & $275(77.7)$ & - & $4.094(1.441-11.631)$ & 0.014 & $4.050(1.333-12.314)$ & 0.140 \\
\hline \multicolumn{8}{|l|}{ Increased Overjet } \\
\hline Present & $16(13.9)$ & $99(86.1)$ & 0.057 & 1 & - & - & - \\
\hline Absent & $67(22.3)$ & $233(77.7)$ & - & $1.779(0.982-3.222)$ & - & - & - \\
\hline \multicolumn{8}{|l|}{ Increased Overbite } \\
\hline Present & $7(10.8)$ & $58(89.2)$ & 0.048 & 1 & - & - & - \\
\hline Absent & $76(21.7)$ & $274(78.3)$ & & $2.298(1.008-5.241)$ & - & - & - \\
\hline Type of Preschool & & & & & & & \\
\hline Public & 48 (21.0) & $181(79.0)$ & 0.587 & 1 & - & - & - \\
\hline Private & 35 (18.8) & $151(81.2)$ & - & $0.874(0.537-1.421)$ & - & - & - \\
\hline Parent/Caregiver age & & & & & & & \\
\hline$>30$ years & $24(12.4)$ & $169(87.6)$ & $<0.001$ & 1 & 0.027 & 1 & - \\
\hline$\leq 30$ years & $59(26.6)$ & $163(73.4)$ & - & $2.549(1.514-4.292)$ & - & $2.936(1.077-3.478)$ & 0.176 \\
\hline Mother's schooling & & & & & & & \\
\hline$>8$ years & 49 (19.8) & 198(80.2) & 0.920 & 1 & - & - & - \\
\hline$\leq 8$ years & $34(20.2)$ & $134(79.8)$ & - & $1.025(0.629-1.672)$ & - & - & - \\
\hline Perception of general health & & & & & & & \\
\hline Good & $62(18.0)$ & $282(82.0)$ & 0.028 & 1 & - & - & - \\
\hline Poor & $21(29.6)$ & $50(70.4)$ & - & 1.910 (1.071-3.409) & - & - & - \\
\hline Perception of oral health & & & & & & & \\
\hline Good & $44(14.1)$ & $267(85.9)$ & $<0.001$ & 1 & 0.029 & 1 & \\
\hline Poor & 39 (37.5) & $65(62.5)$ & - & $3.641(2.188-6.058)$ & - & $1.973(1.072-3.634)$ & 0.253 \\
\hline History of dental visit & & & & & & & \\
\hline No & $51(16.8)$ & $252(83.8)$ & 0.009 & 1 & - & - & - \\
\hline Yes & $32(28.6)$ & $80(71.4)$ & - & $1.976(1.189-3.287)$ & - & - & - \\
\hline History of tooth pain & & & & & & & \\
\hline No & 38 (12.7) & $261(87.3)$ & $<0.001$ & 1 & 0.001 & 1 & - \\
\hline Yes & 45 (38.8) & $71(61.2)$ & - & $4.353(2.627-7.215)$ & - & $2.666(1.492-4.765)$ & 0.293 \\
\hline
\end{tabular}

"Unadjusted conditional logistic regression analysis; "Variables incorporated in multivariate model $(p<0.20)$ : dental caries, caries severity, malocclusion, anterior open bite, increased overbite, increased overjet, parent's/caregiver's age, parent's/caregiver's perception of child's general health, parent's/caregiver's perception of child's oral health, history of dental visit, and history of tooth pain 
association has been described in previous studies ${ }^{10,33}$ as well as in a systematic review of the literature. ${ }^{34}$ Younger parents/caregivers may have less professional stability ${ }^{35}$ or less experience in taking care of their children, which can contribute to feelings of insecurity. ${ }^{17}$ In this context, early counseling programs targeting this population can empower parents regarding this issue ${ }^{36}$ and may help reduce the occurrence of these feelings.

Parents/caregivers who rated their child's oral health as "poor" were more likely to experience an impact on quality of life, which is consistent with data reported in previous cross-sectional studies. ${ }^{8,13,37}$ Poorer perceptions of the child's oral health have been associated with the presence of tooth decay, low parental schooling, low household income, and feelings of guilt. ${ }^{1,8,37}$ Such perceptions are also a strong indicator of the use of dental care services. ${ }^{1,38}$ Therefore, investigating this issue is important for clinicians as it may enable them to improve children's oral health and quality of life. ${ }^{5}$

TDI did not exert an impact on the OHRQoL of the families, as there were no statistically significant differences in the distribution of this condition among cases and controls. The literature offers divergent findings on this issue, ${ }^{10,13,39}$ but there is a tendency for only severe injuries such as fractures involving the pulp, avulsion, and/or luxation to be predictors of negative impact on a family's quality of life. ${ }^{13,40}$ The greater frequency of enamel fractures in the children included in the present study may explain the lack of an association.

This study is limited by its retrospective nature, and recall bias may have influenced the parents'/caregivers' responses. However, besides its original design,

\section{References}

1. Talekar BS, Rozier RG, Slade GD, EnnettST. Parental perceptions of their preschool-aged children's oral health. J Am Dent Assoc. 2005;136(3):364-72. doi:10.14219/jada.archive.2005.0179

2. Pahel BT, Rozier RG, Slade GD. Parental perceptions of children's oral health: the Early Childhood Oral Health Impact Scale (ECOHIS). Health Qual Life Outcomes. 2007;5(1):6. doi:10.1186/1477-7525-5-6

3. Berger TD, Kenny DJ, Casas MJ, Barrett EJ, Lawrence HP. Effects of severe dentoalveolar trauma on the quality-of-life of children and parents. Dent Traumatol. 2009;25(5):462-9. doi:10.1111/j.1600-9657.2009.00809.x the 1:4 ratio used to pair cases and controls may be considered a strength as it allowed a bigger sample size, therefore increasing the accuracy and statistical power of the study. ${ }^{12}$ Other strengths of this investigation include the use of a validated measure and the sampling process. Children were randomly selected from a representative sample of public and private preschools proportionally selected from all the administrative districts of the city of Campina Grande. Thus, we cautiously recommend the extrapolation of these findings to the population.

Our results strengthen the evidence that children's oral health problems reverberate beyond their clinical aspects. Improving access to dental care may prevent disease progression, thereby reducing family consequences and benefiting the state by reducing health costs and loss of productivity.

\section{Conclusion}

High caries severity, toothache, parental rating of the child's oral health as poor, and younger parents/caregivers were associated with a negative impact on the family's quality of life. Anterior open bite was a protective factor for family impact.

\section{Acknowledgments}

This study was supported by the State University of Paraíba (UEPB), the Brazilian Coordination of Higher Education, Ministry of Education (CAPES), the Research Foundation of the State of Minas Gerais (FAPEMIG), and the National Council for Scientific and Technological Development (CNPQ), Brazil (Process \# 471-790.2011/7).
4. Paula JS, Leite IC, Almeida AB, Ambrosano GM, Mialhe FL. The impact of socioenvironmental characteristics on domains of oral health-related quality of life in Brazilian schoolchildren. BMC Oral Health. 2013;13(1):10. doi:10.1186/1472-6831-13-10

5. Abanto J, Carvalho TS, Mendes FM, Wanderley MT, Bönecker M, Raggio DP. Impact of oral diseases and disorders on oral health-related quality of life of preschool children. Community Dent Oral Epidemiol. 2011;39(2):105-14. doi:10.1111/j.1600-0528.2010.00580.x 
6. Abanto J, Paiva SM, Raggio DP, Celiberti P, Aldrigui JM, Bönecker $\mathrm{M}$. The impact of dental caries and trauma in children on family quality of life. Community Dent Oral Epidemiol. 2012;40(4):323-31. doi:10.1111/j.1600-0528.2012.00672.x

7. Carvalho TS, Abanto J, Mendes FM, Raggio DP, Bönecker M. Association between parental guilt and oral health problems in preschool children. Braz Oral Res. 2012;26(6):557-63. doi:10.1590/S1806-83242012000600012

8. Gomes MC, Clementino MA, Pinto-Sarmento TC, Martins CC, Granville-Garcia AF, Paiva SM. Association between parental guilt and oral health problems in preschool children: a hierarchical approach. BMC Public Health. 2014;14(1):854. doi:10.1186/1471-2458-14-854

9. Viegas CM, Paiva SM, Carvalho AC, Scarpelli AC, Ferreira FM, Pordeus IA. Influence of traumatic dental injury on quality of life of Brazilian preschool children and their families. Dent Traumatol. 2014;30(5):338-47. doi:10.1111/edt.12091

10. Scarpelli AC, Paiva SM, Viegas CM, Carvalho AC, Ferreira FM, Pordeus IA. Oral health-related quality of life among Brazilian preschool children. Community Dent Oral Epidemiol. 2013;41(4):336-44. doi:10.1111/cdoe.12022

11. Levin KA. Study design V. Case-control studies. Evid Based Dent. 2006;7(3):83-4. doi:10.1038/sj.ebd.6400436

12. Garey KW. The role of matching in epidemiologic studies. Am J Pharm Educ. 2004;68(3):83. doi:10.5688/aj680383

13. Gomes MC, Pinto-Sarmento TC, Costa EM, Martins CC, Granville-Garcia AF, Paiva SM. Impact of oral health conditions on the quality of life of preschool children and their families: a cross-sectional study. Health Qual Life Outcomes. 2014;12(1):55. doi:10.1186/1477-7525-12-55

14. Instituto Brasileiro de Geografia e Estatística - IBGE. Cidades. Paraíba: Campina Grande. Rio de Janeiro: Instituto Brasileiro de Geografia e Estatística ; 2015 [cited 2015 Nov 18]. Available from: http://cidades.ibge.gov.br/xtras/perfil.php?la $\mathrm{ng}=\& \operatorname{codmun}=250400 \&$ search=paraiba $\mid$ campina-grande

15. Daniel WW, Cross CL. Biostatistics: a foundation for analysis in the health sciences. 10th ed. Danvers: John Wiley \& Sons; 2013.

16. Lwanga SK, Lemeshow S. Sample size determination in health studies: a practical manual. Geneva: World Health Organization; 1991.

17. Martins-Júnior PA, Ramos-Jorge J, Paiva SM, Marques LS, Ramos-Jorge ML. Validations of the Brazilian version of the early childhood oral health impact scale (ECOHIS). Cad Saúde Pública. 2012;28(2):367-74. doi:10.1590/S0102-311X2012000200015

18. Scarpelli AC, Oliveira BH, Tesch FC, Leão AT, Pordeus IA, Paiva SM. Psychometric properties of the Brazilian version of the Early Childhood Oral Health Impact Scale (B-ECOHIS). BMC Oral Health. 2011;11(1):19. doi:10.1186/1472-6831-11-19

19. Tesch FC, Oliveira BH, Leão A. [Semantic equivalence of the Brazilian version of the Early Childhood Oral Health Impact Scale]. Cad Saúde Pública. 2008;24(8):1897-909. Portuguese. doi:10.1590/S0102-311X2008000800018
20. Ramos-Jorge J, Pordeus IA, Ramos-Jorge ML, Marques LS, Paiva SM. Impact of untreated dental caries on quality of life of preschool children: different stages and activity. Community Dent Oral Epidemiol. 2014;42(4):311-22. doi:10.1111/cdoe.12086

21. Altman DG. Practical statistics for medical research. 2nd ed. London: Chapman and Hall; 2006.

22. Ismail AI, Sohn W, Tellez M, Sen A, Hasson $\mathrm{H}$ et al. The International Caries Detection and Assessment System (ICDAS): an integrated system for measuring dental caries. Community Dent Oral Epidemiol. 2007;35(3):170-8. doi:10.1111/j.1600-0528.2007.00347.x

23. Andreasen JO, Andreasen FM, Andersson L. Textbook and Color Atlas of Traumatic Injuries to the Teeth. 4th ed. Oxford: Willey-Blackwell; 2007.

24. Foster TD, Hamilton MC. Occlusion in the primary dentition: study of children at 2 and one-half to 3 years of age. Br Dent J. 1969;126(2):76-9.

25. Grabowski R, Stahl F, Gaebel M, Kundt G. [Relationship between occlusal findings and orofacial myofunctional status in primary and mixed dentition. Part I: Prevalence of malocclusions/. J Orofac Orthop. 2007;68(1):26-37. German. doi:10.1007/s00056-007-1606-0

26. Ramos-Jorge ML, Bosco VL, Peres MA, Nunes AC. The impact of treatment of dental trauma on the quality of life of adolescents - a case-control study in Southern Brazil. Dent Traumatol. 2007;23(2):114-9. doi:10.1111/j.1600-9657.2005.00409.x

27. Bernabé E, Sheiham A, de Oliveira CM. Impacts on daily performances attributed to malocclusions by British adolescents. J Oral Rehabil. 2009;36(1):26-31. doi:10.1111/j.1365-2842.2008.01899.x

28. Bendo CB, Paiva SM, Varni JW, Vale MP. Oral health-related quality of life and traumatic dental injuries in Brazilian adolescents. Community Dent Oral Epidemiol. 2014;42(3):216-23. doi:10.1111/cdoe.12078

29. Ferraz NK, Nogueira LC, Pinheiro ML, Marques LS, Ramos-Jorge ML, Ramos-Jorge J. Clinical consequences of untreated dental caries and toothache in preschool children. Pediatr Dent. 2014;36(5):389-92. doi:

30. Amin MS, Harrison RL. Understanding parents' oral health behaviors for their young children. Qual Health Res. 2009;19(1):116-27. doi:10.1177/1049732308327243

31. Heimer MV, Tornisiello Katz CR, Rosenblatt A. Non-nutritive sucking habits, dental malocclusions, and facial morphology in Brazilian children: a longitudinal study. Eur J Orthod. 2008;30(6):580-5. doi:10.1093/ejo/cjn035

32. Marter A, Agruss JC. Pacifiers: an update on use and misuse. J Spec Pediatr Nurs. 2007;12(4):278-85. doi:10.1111/j.1744-6155.2007.00126.x

33. Martins-Júnior PA, Vieira-Andrade RG, Corrêa-Faria P, Oliveira-Ferreira F, Marques LS, Ramos-Jorge, ML. Impact of early childhood caries on the oral health-related quality of life of preschool children and their parents. Caries Res. 2013;47(3):211-8. doi:10.1159/000345534 
34. Kumar S, Kroon J, Lalloo R. A systematic review of the impact of parental socio-economic status and home environment characteristics on children's oral health related quality of life. Health Qual Life Outcomes. 2014;12(1):41. doi:10.1186/1477-7525-12-4

35. Raatikainen K, Heiskanen N, Heinonen S. Does unemployment in family affect pregnancy outcome in conditions of high quality maternity care? BMC Public Health. 2006;6(1):46. doi:10.1186/1471-2458-6-46

36. Minah G, Lin C, Coors S, Rambob I, Tinanoff N, Grossman LK. Evaluation of an early childhood caries prevention program at an urban pediatric clinic. Pediatr Dent. 2008;30(6):499-504.

37. Piovesan C, Marquezan M, Kramer PF, Bönecker M, Ardenghi T. Socioeconomic and clinical factors associated with caregivers' perceptions of children's oral health in Brazil. Community Dent Oral Epidemiol. 2011;39(3):260-7. doi:10.1111/j.1600-0528.2010.00598.x
38. Goettems ML, Ardenghi TM, Demarco FF, Romano AR, Torriani DD. Children's use of dental services: influence of maternal dental anxiety, attendance pattern, and perception of children's quality of life. Community Dent Oral Epidemiol. 2012;40(5):451-8. doi:10.1111/j.1600-0528.2012.00694.x

39. Abanto J, Tello G, Bonini GC, Oliveira LB, Murakami C, Bönecker M. Impact of traumatic dental injuries and malocclusions on quality of life of preschool children: a population-based study. Int J Paediatr Dent. 2015;25(1):18-28. doi:10.1111/ipd.12092

40. Aldrigui JM, Abanto J, Carvalho TS, Mendes FM, Wanderley MT, Bönecker M, et al. Impact of traumatic dental injuries and malocclusions on quality of life of young children. Health Qual Life Outcomes. 2011;9(1):78. doi:10.1186/1477-7525-9-78 